\title{
Theoretical Analysis, Synthesis, and Characterization of 2D W1.33C (MXene) with Ordered Vacancies
}

Rahele Meshkian, Hans Lind, Joseph Halim, Ahmed El Ghazaly, Jimmy Thörnberg, Quanzheng Tao, Martin Dahlqvist, Justinas Palisaitis, Per O A Persson and Johanna Rosén

The self-archived postprint version of this journal article is available at Linköping University Institutional Repository (DiVA):

http://urn.kb.se/resolve?urn=urn:nbn:se:liu:diva-163485

N.B.: When citing this work, cite the original publication.

Meshkian, R., Lind, H., Halim, J., El Ghazaly, A., Thörnberg, J., Tao, Q., Dahlqvist, M., Palisaitis, J., Persson, P. O A, Rosén, J., (2019), Theoretical Analysis, Synthesis, and Characterization of 2D W1.33C (MXene) with Ordered Vacancies, ACS APPLIED NANO MATERIALS, 2(10), 6209-6219.

https://doi.org/10.1021/acsanm.9bo1107

Original publication available at:

https://doi.org/10.1021/acsanm.9bo1107

Copyright: American Chemical Society

http://pubs.acs.org/ 


\section{Theoretical analysis, synthesis and characterization of $2 \mathrm{D} \mathrm{W} \mathrm{W}_{1.33} \mathrm{C}$ (MXene) with ordered vacancies}

Rahele Meshkian, Hans Lind, Joseph Halim, Ahmed El Ghazaly, Jimmy Thörnberg, Quanzheng

Tao, Martin Dahlqvist, Justinas Palisaitis, Per O. A. Persson, Johanna Rosen*

Thin Film Physics, Department of Physics, Chemistry and Biology (IFM), Linköping University, SE-581 83 Linköping, Sweden

* corresponding authors

johanna.rosen@liu.se

KEYWORDS: MXene, $i$-MAX, XPS, DFT, electrochemistry 


\section{ABSTRACT}

Synthesis of delaminated $2 \mathrm{D} \mathrm{W} \mathrm{W}_{1.33} \mathrm{C}$ (MXene) has been performed by selectively etching $\mathrm{Al}$ as well as $\mathrm{Sc} / \mathrm{Y}$ from the recently discovered nanolaminated $i$-MAX phases $\left(\mathrm{W}_{2 / 3} \mathrm{Sc}_{1 / 3}\right)_{2} \mathrm{AlC}$ and $\left(\mathrm{W}_{2 / 3} \mathrm{Y}_{1 / 3}\right)_{2} \mathrm{AlC}$. Both quaternary phases produce MXenes with similar flake morphology, and with a skeletal structure due to formation of ordered vacancies. The measured $\mathrm{O}, \mathrm{OH}$, and $\mathrm{F}$ terminations, however, differ in amount as well as in relative ratios, depending on parent material, evident from X-ray photoelectron spectroscopy. These findings are correlated to theoretical simulations based on first principles, investigating the $\mathrm{W}_{1.33} \mathrm{C}$ and the effect of termination configurations on structure, formation energy, stability, and electronic structure. The theoretical results indicate a favored F-rich surface composition, though with a system going from insulating/semiconducting to metallic for different termination configurations, suggesting a high tuning potential of these materials. Additionally, free-standing $\mathrm{W}_{1.33} \mathrm{C}$ films of $2-4 \mu \mathrm{m}$ thickness and with up to $10 \mathrm{wt} \%$ polymer (PEDOT:PSS) was tested as electrodes in supercapacitors, showing capacitances up to $600 \mathrm{~F} \mathrm{~cm}^{-3}$ in $1 \mathrm{M} \mathrm{H}_{2} \mathrm{SO}_{4}$ and high capacitance retention for at least 10000 cycles at $10 \mathrm{~A} \mathrm{~g}^{-1}$. This is highly promising results compared to other $\mathrm{W}$-based materials to date. 


\section{INTRODUCTION}

After the discovery of graphene by Novoselov and Geim in $2004,{ }^{1}$ the interest in two-dimensional (2D) materials have increased tremendously, with diverse properties and potential applications reported for, e.g., hexagonal boron nitrides, $\mathrm{h}-\mathrm{BN},{ }^{2}$ and transition metal dichalcogenides, such as $\mathrm{MoS}_{2},{ }^{3} \mathrm{WS}_{2},{ }^{4}$ and $\mathrm{WSe}_{2}{ }^{5}$ In 2011, a new class of $2 \mathrm{D}$ compounds were discovered, ${ }^{6,7}$ displaying the very useful combination of a high electrical conductivity and hydrophilicity. These compounds were called MXenes, as produced from chemical extraction of the A-layer from the parent $M_{n+1} A X_{n}$ (MAX) phases, which in turn are composed of a transition metal, $M$, an A group element, $A$, and carbon or nitrogen, $X$, and with $n=1-3 .{ }^{8}$ Upon the etching treatment, the removed Al-layers are replaced by terminations $(\mathrm{T})$ in the form of $\mathrm{O}(\mathrm{H})$ and $\mathrm{F},{ }^{6,9}$ and the general MXene formula is therefore $\mathrm{M}_{n+1} \mathrm{XT}_{x}$, where $\mathrm{x}$ denotes the number of terminations per formula unit. These $2 \mathrm{D}$ materials, to date primarily realized from MAX phases, have shown great promise for energy storage, e.g. as material in electrodes for Li-ion batteries ${ }^{9,10}$ and supercapacitors ,, $, 11,12$ and electromagnetic interference shielding. ${ }^{13}$

MXenes stand out among 2D materials through their diverse chemistry, both with respect to their intrinsic composition and their different surface terminations. This gives them a key advantage through the tuning potential of their properties. For example, theoretical predictions suggest that the electronic structure of MXenes can be altered between being insulating, metallic or semiconducting, through a change in the surface terminations. ${ }^{14,15}$

The intrinsic chemistry of the MXene is controlled by the precursor material, for which alloying is one way of expanding the parameter space of attainable properties. Typically, the alloy is a MAX phase solid solution, with two $M$ elements randomly mixed on the $M$-site. In 2014, however, a chemically ordered MAX phase was discovered, $\left(\mathrm{Cr}_{2 / 3} \mathrm{Ti}_{1 / 3}\right)_{3} \mathrm{AlC}_{2}$, composed of two $M$ elements 
in a 2:1 ratio displaying out-of-plane order through alternating layers composed of one $\mathrm{M}$ element only. ${ }^{16}$ Such ordered phases were converted into MXenes. ${ }^{17,}{ }^{18}$ In 2017, ordering between of $M$ elements of the same 2:1 ratio was discovered in a $M_{2} A X$ phase, though this time with an in-plane chemical arrangement. ${ }^{12,} 19$ This finding spurred the notation $o$-MAX vs $i$-MAX, to make a distinction between the two groups of chemically ordered materials. Most importantly, the $i$-MAX phases was shown to realize a MXene with either in-plane chemical ordering, ${ }^{20}$ or vacancy ordering through removal of the minority $M$ element together with the $A$ element. ${ }^{12}$ The latter MXene, $\mathrm{Mo}_{1.33} \mathrm{C}$ from the $i$-MAX $\left(\mathrm{Mo}_{2 / 3} \mathrm{Sc}_{1 / 3}\right)_{2} \mathrm{AlC}$, has shown a high potential for supercapacitor applications. $^{12,21}$

The $i$-MAX phases have allowed incorporation of elements previously not used for MAX phases and MXenes. The most recent example is $\mathrm{W}$, forming the two $i$-MAX phases $\left(\mathrm{W}_{2 / 3} \mathrm{Sc}_{1 / 3}\right)_{2} \mathrm{AlC}$ and $\left(\mathrm{W}_{2 / 3} \mathrm{Y}_{1 / 3}\right)_{2} \mathrm{AlC}$, which in turn are used to produce $\mathrm{W}_{1.33} \mathrm{C}$ MXene with vacancy ordering from etching of $\mathrm{Al}$ and $\mathrm{Sc} / \mathrm{Y} .{ }^{22}$ see schematic in Figure 1. This discovery was sprung from theoretical simulations with subsequent experimental verification, including initial tests showing promise for hydrogen evolution reaction (HER).

Being most recently discovered, and including an element (W) unexplored in the field of MAX/MXene materials, strongly motivates exploration of the materials characteristics, particularly considering that the W-C bond is known to be extremely strong. ${ }^{23}$ In the present work, we use first principles calculations combined with experiments to fully characterize the structure and composition of vacancy-MXenes originating from both $\left(\mathrm{W}_{2 / 3} \mathrm{Sc}_{1 / 3}\right)_{2} \mathrm{AlC}$ and $\left(\mathrm{W}_{2 / 3} \mathrm{Y}_{1 / 3}\right)_{2} \mathrm{AlC}$, including identification and quantification of the surface terminations. This is correlated to simulations of stability and calculated electronic structure. Furthermore, we evaluate the 
electrochemical performance with respect to supercapacitor applications and find a highly promising material compared to previously reported W-based materials.

\section{RESULTS AND DISCUSSION}

Materials synthesis and structural characterization. Materials synthesis of $\left(\mathrm{W}_{2 / 3} \mathrm{Sc}_{1 / 3}\right)_{2} \mathrm{AlC}$ and $\left(\mathrm{W}_{2 / 3} \mathrm{Y}_{1 / 3}\right)_{2} \mathrm{AlC} i$-MAX was performed by pressureless sintering, see Methods. A scanning transmission electron microscopy (STEM) image of $\left(\mathrm{W}_{2 / 3} \mathrm{Sc}_{1 / 3}\right)_{2} \mathrm{AlC}$ along the [110] zone axis is shown in Figure 1a, with the corresponding schematic expected assuming a monoclinic $C 2 / c$ structure shown in Figure 1b. The characteristic feature of the $i$-MAX, with the minority $M$ element ( $\mathrm{Sc}$ ) extending out from the majority M element (W) planes towards the $A$ layer (Al), is indicated, together with the alternating contrast in the $A$ layer showing Kagomé-like ordering. Powder X-ray diffraction of $\left(\mathrm{W}_{2 / 3} \mathrm{Sc}_{1 / 3}\right)_{2} \mathrm{AlC}$ and $\left(\mathrm{W}_{2 / 3} \mathrm{Y}_{1 / 3}\right)_{2} \mathrm{AlC}$ is shown in Figure S1a and c. In line with previous work, ${ }^{22}$ both these phases were used as parent material for a W-MXene with vacancy-ordering, see schematic in Figure 1c and d. After etching in 48\% hydrofluoric acid (HF) and subsequently intercalating with tetrabutylammonium hydroxide (TBAOH), the derived multilayer MXene flakes delaminate spontaneously in water. To produce freestanding "paper" or films for further analysis, the colloidal suspension is filtered through a nanoporous membrane, see XRD and a SEM cross section of such films in Figure S1. The vacancy-ordering for both W-based MXenes are shown by high-resolution STEM imaging in Figure $1 \mathrm{e}$ and $\mathrm{f}$ originating from the $\left(\mathrm{W}_{2 / 3} \mathrm{Sc}_{1 / 3}\right)_{2} \mathrm{AlC}$ and $\left(\mathrm{W}_{2 / 3} \mathrm{Y}_{1 / 3}\right)_{2} \mathrm{AlC} i$-MAX phases, respectively. The vacancy ordering is evident from the meandering appearance of remaining $\mathrm{W}$ atoms but can additionally be seen in the associated Fast Fourier Transforms (FFTs) where weak reflections appear between the dominating 
hexagonal structure as a consequence of the ordered vacancies. It should also be noted that both MXenes display areas with etching related defects.
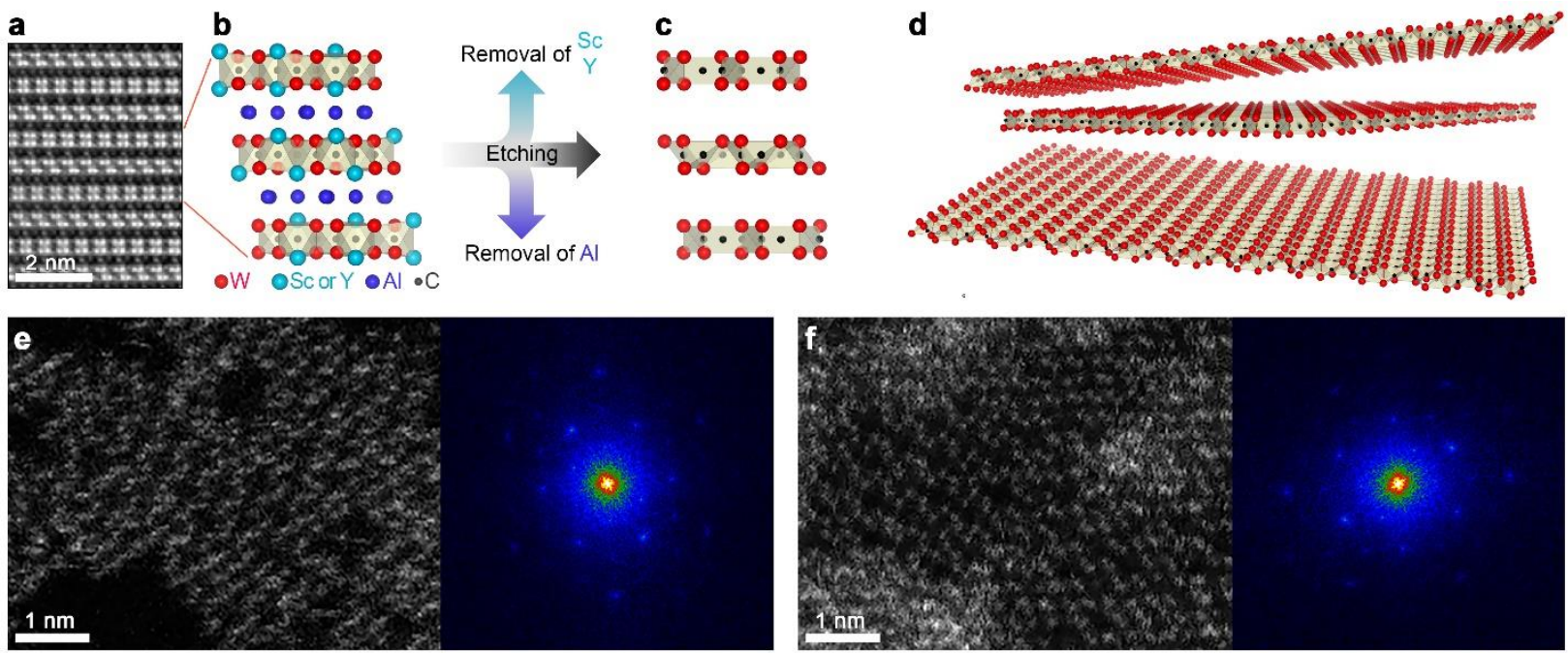

Figure 1. (a) High Resolution STEM image of ( $\left.\mathrm{W}_{2 / 3} \mathrm{Sc}_{1 / 3}\right)_{2} \mathrm{AlC}$ along [100] zone axis. Schematics showing (b) in-plane chemical ordering in $\left(\mathrm{W}_{2 / 3} \mathrm{Sc}_{1 / 3}\right)_{2} \mathrm{AlC}$ or $\left(\mathrm{W}_{2 / 3} \mathrm{Y}_{1 / 3}\right)_{2} \mathrm{AlC} i$-MAX phases, (c) leading to $\mathrm{W}_{1.33} \mathrm{C}$ MXene with ordered divacancies after selective etching and (d) delamination. Surface terminations have been excluded from the schematics. The high-resolution STEM images (top view of single flake) obtained from the vacancy ordered $\mathrm{W}_{1.33} \mathrm{C}$ MXenes originating from the $\left(\mathrm{W}_{2 / 3} \mathrm{Sc}_{1 / 3}\right)_{2} \mathrm{AlC}$ and $\left(\mathrm{W}_{2 / 3} \mathrm{Y}_{1 / 3}\right)_{2} \mathrm{AlC} i$-MAX phases are shown in (e) and (f), respectively, together with their associated FFT.

\section{Chemical characterization through X-ray photoelectron spectroscopy. X-ray}

photoelectron spectroscopy (XPS) measurements performed on cold pressed discs of the $i$-MAX phases $\left(\mathrm{W}_{2 / 3} \mathrm{Sc}_{1 / 3}\right)_{2} \mathrm{AlC}$ and $\left(\mathrm{W}_{2 / 3} \mathrm{Y}_{1 / 3}\right)_{2} \mathrm{AlC}$ as well as $d-\mathrm{W}_{1.33} \mathrm{CT}_{\mathrm{x}}(\mathrm{Sc})$ and $d-\mathrm{W}_{1.33} \mathrm{CT}_{\mathrm{x}}(\mathrm{Y})$ freestanding MXene films were used to identify and quantify the various chemical and terminating species. High resolution spectra for $\mathrm{W} 4 \mathrm{f}, \mathrm{C} 1 \mathrm{~s}, \mathrm{Al} 2 \mathrm{p}$ and $\mathrm{Sc} 2 \mathrm{p}$ for $\left(\mathrm{W}_{2 / 3} \mathrm{Sc}_{1 / 3}\right)_{2} \mathrm{AlC} i$-MAX phase are shown in Figure S2, and high resolution spectra for $\mathrm{W} 4 \mathrm{f}, \mathrm{C} 1 \mathrm{~s}, \mathrm{Al} 2 \mathrm{p}$ and $\mathrm{Y} 3 \mathrm{~d}$ for 
$\left(\mathrm{W}_{2 / 3} \mathrm{Y}_{1 / 3}\right)_{2} \mathrm{AlC} i$-MAX are shown in Figure S3. High-resolution XPS spectra peak fittings for $\mathrm{W}$ 4f, C1s, O1s, F 1s, Al 2p and Y 3d for i) $\mathrm{W}_{1.33} \mathrm{CT}_{\mathrm{x}}(\mathrm{Sc})$ and ii) $\mathrm{W}_{1.33} \mathrm{CT}_{\mathrm{x}}(\mathrm{Y})$ are shown in Figure 2a, b, c, d, e and f, respectively. It should be noted that the general MXene formula, $\mathrm{M}_{n+1} \mathrm{XT}_{x}$, will be used for the analysis and discussion on the XPS results, while in the rest of the paper, "T $\mathrm{x}_{\mathrm{x}}$ " will be omitted. The peak fitting results for various species and the elemental compositions extracted from the high-resolution spectra are tabulated in Tables S1 to S7 in Supporting information.

The high-resolution XPS spectrum of the $\mathrm{W} 4 \mathrm{f}$ region (Figure 2a and Table S2) for $\mathrm{W}_{1.33} \mathrm{CT}_{\mathrm{x}}$ (Sc) was fit by components corresponding to the following species: $\left(\mathrm{W}_{2 / 3} \mathrm{Sc}_{1 / 3}\right)_{2} \mathrm{AlC}, \mathrm{C}-\mathrm{W}-\mathrm{T}_{\mathrm{x}}$, $\mathrm{WO}_{3}$, and $\mathrm{C}-\mathrm{W}-\mathrm{F}_{\mathrm{x}}$. The peaks corresponding to $\mathrm{WO}_{3}$ occupying $15 \%$ of the $\mathrm{W} 4 \mathrm{f}$ region arises from surface oxidation of the film sample. ${ }^{24}$ The peak of $\mathrm{W} 4 \mathrm{f}_{7 / 2}$ corresponding to $\left(\mathrm{W}_{2 / 3} \mathrm{Sc}_{1 / 3}\right)_{2} \mathrm{AlC}$ at a binding energy (BE) of $31.5 \mathrm{eV}$ was attributed to traces of leftover MAX phase, representing $1 \%$ of the $\mathrm{W} 4 \mathrm{f}$ region. This peak is in a similar position to that for $\mathrm{WC}$, reported at a $\mathrm{BE}$ of 31.6 $\mathrm{eV} .{ }^{25}$ The peaks for $\mathrm{W} 4 \mathrm{f}_{7 / 2}$ located at BEs 32.9 and $38.3 \mathrm{eV}$ belongs to the $\mathrm{W}_{1.33} \mathrm{CT}_{\mathrm{x}}$ compound with a mixed surface termination of $\mathrm{O}, \mathrm{OH}$ and/or $\mathrm{F}$, and $\mathrm{W}_{1.33} \mathrm{CF}_{\mathrm{x}}$ compound with only $\mathrm{F}$ surface termination, respectively. The $\mathrm{BE}$ of the $\mathrm{W} 4 \mathrm{f}_{7 / 2}$ belonging to $\mathrm{W}_{1.33} \mathrm{CT}_{\mathrm{x}}$ is at a $\mathrm{BE}$ which is $1.4 \mathrm{eV}$ higher than for $\left(\mathrm{W}_{2 / 3} \mathrm{Sc}_{1 / 3}\right)_{2} \mathrm{AlC}$ (Figure $\mathrm{S} 2 \mathrm{a}$ ). This shift to higher BEs for MXenes, compared to their parent MAX phases and carbides is due to the replacement of the " $\mathrm{A}$ " element by more electronegative species: $\mathrm{O}, \mathrm{OH}$ and/or $\mathrm{F}$. The $\mathrm{BE}$ of the $\mathrm{W} 4 \mathrm{f}_{7 / 2}$ belonging to $\mathrm{W}_{1.33} \mathrm{CF}_{\mathrm{x}}$ is close to that reported for $\mathrm{WF}_{6}$ (38.0 to $\left.39.9 \mathrm{eV}\right){ }^{26,27}$ The high resolution XPS spectrum of the $\mathrm{W} 4 \mathrm{f}$ region (Figure 2a and Table $\mathrm{S} 2$ ) for $\mathrm{W}_{1.33} \mathrm{CT}_{\mathrm{x}}(\mathrm{Y})$ was fit by components corresponding to the following species: $\mathrm{C}-\mathrm{W}-\mathrm{T}_{\mathrm{x}}, \mathrm{WO}_{3}$, and $\mathrm{C}-\mathrm{W}-\mathrm{F}_{\mathrm{x}}$, equivalent to those for $\mathrm{W}_{1.33} \mathrm{CT}_{\mathrm{x}}(\mathrm{Sc})$. The $\mathrm{BE}$ of $\mathrm{C}-\mathrm{W}-\mathrm{T}_{\mathrm{x}}$ species in $\mathrm{W}_{1.33} \mathrm{CT}_{\mathrm{x}}(\mathrm{Y})$ is at $32.7 \mathrm{eV}$ which is $1.3 \mathrm{eV}$ higher than the $\mathrm{BE}$ of $\mathrm{W}_{4} 4 \mathrm{f}_{7 / 2}$ in the parent MAX phase $\left(\mathrm{W}_{2 / 3} \mathrm{Y}_{1 / 3}\right)_{2} \mathrm{AlC}$ at $31.4 \mathrm{eV}$ (Figure S3a). This shift is also due to the replacement of 
the " $\mathrm{A}$ " element by $\mathrm{O}, \mathrm{OH}$ and/or F surface termination groups. It is worth noting that the $\mathrm{BE}$ of the $\mathrm{W}_{4} \mathrm{f}_{7 / 2}$ species in both parent $i$-MAX phases $\left(\mathrm{W}_{2 / 3} \mathrm{Sc}_{1 / 3}\right)_{2} \mathrm{AlC}$ and $\left(\mathrm{W}_{2 / 3} \mathrm{Y}_{1 / 3}\right)_{2} \mathrm{AlC}$ is almost the same $\left(31.5 \mathrm{eV}\right.$ for $\mathrm{W}_{4} \mathrm{f}_{7 / 2}$ in $\left(\mathrm{W}_{2 / 3} \mathrm{Sc}_{1 / 3}\right)_{2} \mathrm{AlC}$ and $31.4 \mathrm{eV}$ for $\mathrm{W} 4 \mathrm{f}_{7 / 2}$ in $\left.\left(\mathrm{W}_{2 / 3} \mathrm{Y}_{1 / 3}\right)_{2} \mathrm{AlC}\right)$.

Figure $2 \mathrm{~b}$ shows the high-resolution XPS spectra of $\mathrm{C} 1 \mathrm{~s}$ region for i) $\mathrm{W}_{1.33} \mathrm{CT}_{\mathrm{x}}(\mathrm{Sc})$ and ii) $\mathrm{W}_{1.33} \mathrm{CT}_{\mathrm{x}}(\mathrm{Y})$ that was fit by components corresponding to C-W-T $, \mathrm{C}-\mathrm{C}, \mathrm{C}-\mathrm{O}$, and $\mathrm{COO}$ species. The peak located at $283.0 \mathrm{eV}$ for $\mathrm{W}_{1.33} \mathrm{CT}_{\mathrm{x}}(\mathrm{Sc})$ and $282.9 \mathrm{eV}$ for $\mathrm{W}_{1.33} \mathrm{CT}_{\mathrm{x}}(\mathrm{Y})$ belong to carbon species bonded to $\mathrm{W}$ in the $\mathrm{W}_{1.33} \mathrm{CT}_{\mathrm{x}}$ compound, which is at at the same $\mathrm{BE}$ as that for $\mathrm{C}$ in both parent $i$-MAX phases $\left(\mathrm{W}_{2 / 3} \mathrm{Sc}_{1 / 3}\right)_{2} \mathrm{AlC}$ (Figure $\mathrm{S} 2 \mathrm{~b}$ ) and $\left(\mathrm{W}_{2 / 3} \mathrm{Y}_{1 / 3}\right)_{2} \mathrm{AlC}$ (Figure $\mathrm{S} 3 \mathrm{~b}$ ). The other species present in the $\mathrm{C} 1 \mathrm{~s}$ region result from traces of $\mathrm{TBAOH}$ intercalations, and/or the exposure of the MXene to the ambient. ${ }^{28,29}$

Figure 2c plots the high resolution XPS spectra in the $\mathrm{O} 1 \mathrm{~s}$ region for i) $\mathrm{W}_{1.33} \mathrm{CT}_{\mathrm{x}}(\mathrm{Sc})$ and ii) $\mathrm{W}_{1.33} \mathrm{CT}_{\mathrm{x}}(\mathrm{Y})$, both were fit by the same components corresponding to the following species: $\mathrm{WO}_{3}$, $\mathrm{C}-\mathrm{W}-\mathrm{O}_{\mathrm{x}}, \mathrm{C}-\mathrm{W}-(\mathrm{OH})_{\mathrm{x}}, \mathrm{Al}_{\mathrm{x}} \mathrm{F}_{\mathrm{x}}$, and $\mathrm{H}_{2} \mathrm{O}_{\text {ads. }}$. The BEs of all the species were within $\pm 0.1 \mathrm{eV}$ for $\mathrm{W}_{1.33} \mathrm{CT}_{\mathrm{x}}(\mathrm{Sc})$ and $\mathrm{W}_{1.33} \mathrm{CT}_{\mathrm{x}}(\mathrm{Y})$. The $\mathrm{WO}_{3}$ and $\mathrm{AlO}_{\mathrm{x}} \mathrm{F}_{\mathrm{y}}$ species belong to sample surface oxidation and a byproduct of the $\mathrm{Al}$ etching, respectively. The peaks at 531.5, 532.2, and $533.9 \mathrm{eV}$ belong to -O termination, $-\mathrm{OH}$ termination and adsorbed $\mathrm{H}_{2} \mathrm{O}$, respectively. ${ }^{28,} 30$ The high resolution XPS spectrum in the $\mathrm{F} 1 \mathrm{~s}$ region (shown in Figure $2 \mathrm{~d}$ ) for i) $\mathrm{W}_{1.33} \mathrm{CT}_{\mathrm{x}}(\mathrm{Sc})$ was fit by components belonging to $\mathrm{C}-\mathrm{W}-\mathrm{F}_{\mathrm{x}}$ and $\mathrm{AlO}_{\mathrm{x}} \mathrm{F}_{\mathrm{x}}$, and for ii) $\mathrm{W}_{1.33} \mathrm{CT}_{\mathrm{x}}(\mathrm{Y})$ was fit by two components belonging to $\mathrm{C}-\mathrm{W}-\mathrm{F}_{\mathrm{x}}$, and $\mathrm{YF}_{3}$ and/or $\mathrm{AlO}_{\mathrm{x}} \mathrm{F}_{\mathrm{y}}$. The $\mathrm{BE}$ of the $\mathrm{C}-\mathrm{W}-\mathrm{F}_{\mathrm{x}}$ is within $\pm 0.1 \mathrm{eV}$ for both compounds. This species can be attributed to the -F termination in the MXene compound and its BE is close to that reported for fluorine bonded to $\mathrm{W} .{ }^{26,27}$ The high resolution spectrum in the $\mathrm{Al} 2 \mathrm{p}$ region (shown in Figure 2e) for i) $\mathrm{W}_{1.33} \mathrm{CT}_{\mathrm{x}}(\mathrm{Sc})$ was fit by two components belonging to $\left(\mathrm{W}_{2 / 3} \mathrm{Sc}_{1 / 3}\right)_{2} \mathrm{AlC}$ and $\mathrm{AlO}_{\mathrm{x}} \mathrm{F}_{\mathrm{x}}$, and for ii) $\mathrm{W}_{1.33} \mathrm{CT}_{\mathrm{x}}(\mathrm{Y})$ was fit by one component belonging to $\mathrm{AlO}_{\mathrm{x}} \mathrm{F}_{\mathrm{y}}$. Figure $3 \mathrm{f}$ 
shows the high resolution XPS spectrum for the $\mathrm{Y} 3 \mathrm{~d}$ region for $d-\mathrm{W}_{1.33} \mathrm{CT}_{\mathrm{x}}(\mathrm{Y})$, which was fit by two components belonging to $\mathrm{Y}$ in the MXene compound at a $\mathrm{BE}$ of $153.6 \mathrm{eV}$ for $3 \mathrm{~d}_{5 / 2}$, which is at a BE $0.4 \mathrm{eV}$ lower than that of what was reported for metallic $\mathrm{Y} .{ }^{31}$ The second species belong to $\mathrm{YF}_{3},{ }^{32}$ a residue from the etching process.
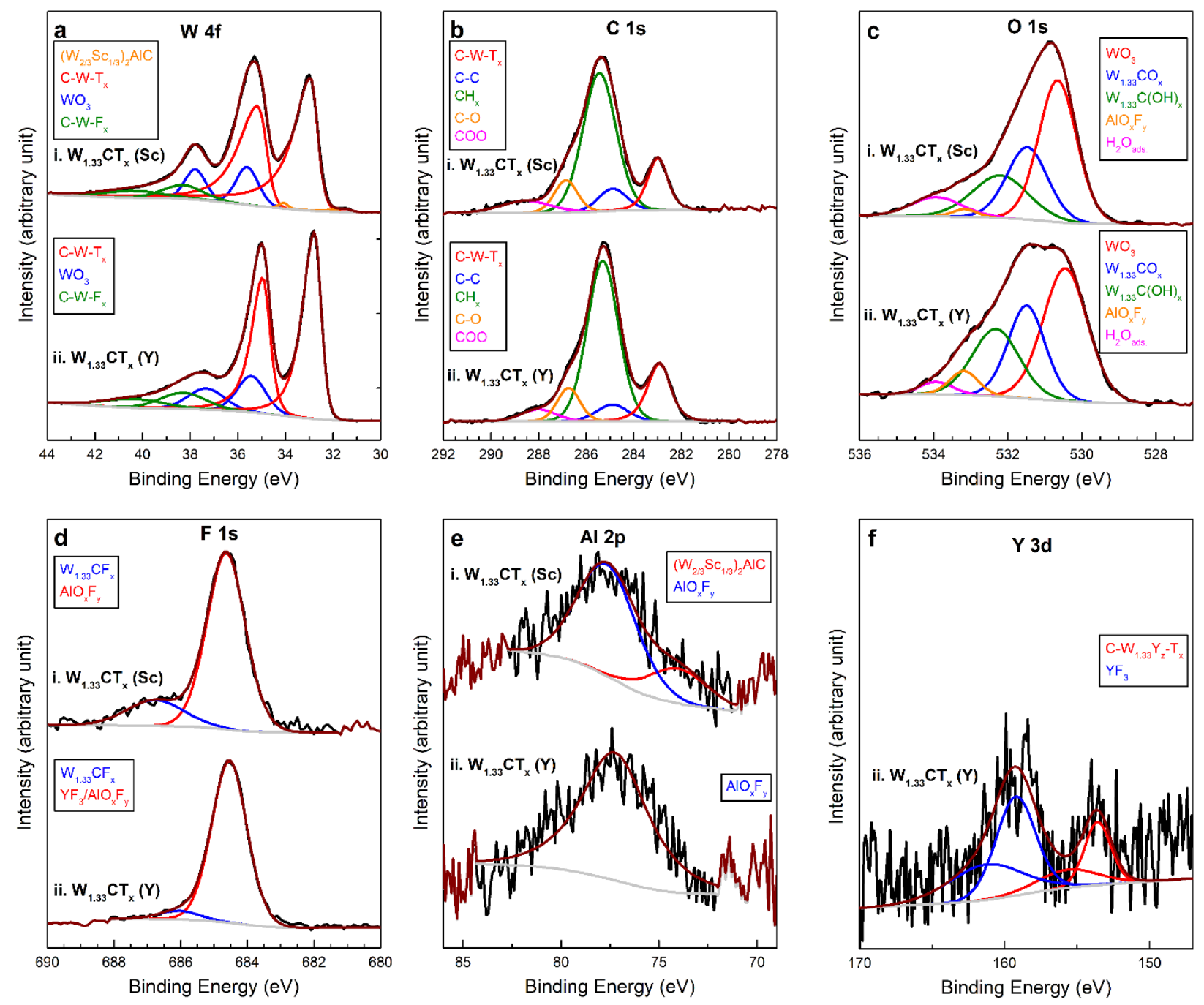

Figure 2. XPS spectra with curve fitting of i) $\mathrm{W}_{1.33} \mathrm{CT}_{\mathrm{x}}(\mathrm{Sc})$ and ii) $\mathrm{W}_{1.33} \mathrm{CT}_{\mathrm{x}}(\mathrm{Y})$ freestanding delaminated films for (a) W 4f, (b) C 1s, (c) O 1s, (d) F 1s, (e) Al 2p, and (f) Y 3d. Various peaks represent various species assumed to exist. Labels and peak colors are coordinated. The peak fitting results are summarized in Tables $\mathrm{S} 1$ to $\mathrm{S} 7$. 
Summarising the above, the chemical formula for $\mathrm{W}_{1.33} \mathrm{CT}_{\mathrm{x}}(\mathrm{Sc})$ and $\mathrm{W}_{1.33} \mathrm{CT}_{\mathrm{x}}(\mathrm{Y})$, based upon the atomic percentage of their elements (Table S1) and the fraction of the species related to the MXene compounds, can be represented as $\mathrm{W}_{1.4} \mathrm{CO}_{0.9}(\mathrm{OH})_{0.7} \mathrm{~F}_{0.3 .} \cdot 0.3 \mathrm{H}_{2} \mathrm{O}_{\text {ads. }}$ and $\mathrm{W}_{1.2} \mathrm{Y}_{0.01} \mathrm{CO}_{0.4}(\mathrm{OH})_{0.4} \mathrm{~F}_{0.4 .} .0 .05 \mathrm{H}_{2} \mathrm{O}_{\text {ads. }}$, respectively (using $\mathrm{C}$ as the base). It should be noted that the Y content is within the margin of error for the XPS analysis. The total number of moles of the surface terminations per unit formula for $\mathrm{W}_{1.33} \mathrm{CT}_{\mathrm{x}}(\mathrm{Sc})$ is higher than that for $\mathrm{W}_{1.33} \mathrm{CT}_{\mathrm{x}}(\mathrm{Y}), 1.9$ vs. 1.2. Considering the error bars for the XPS quantification ( \pm 0.1 for every element), the difference may be reduced, though we speculate that these observations may be due to a different amount of defects, or an initially diverging amount of $\mathrm{OH}$ terminations that recombine during analysis in vacuum. ${ }^{33}$ This, in turn, correlates to the amount of surface terminations. Nonetheless, the amounts of $-\mathrm{O}$ and $-\mathrm{OH}$ terminations for $\mathrm{W}_{1.33} \mathrm{CT}_{\mathrm{x}}(\mathrm{Sc})$ each is more than double that of $-\mathrm{F}$ terminations while in $\mathrm{W}_{1.33} \mathrm{CT}_{\mathrm{x}}(\mathrm{Y})$ the amounts of $-\mathrm{O},-\mathrm{OH}$ and $-\mathrm{F}$ terminations are equal. This shows that the same MXene compound produced from different MAX phase can have different distribution of surface terminations, which in turn is of utmost importance for the property tuning potential. For an explanation thereof, we compare the $\mathrm{W}$ and $\mathrm{C}$ states in the two parent materials. However, we find no difference in the $\mathrm{W}$ and $\mathrm{C} B E$ for the two $i$-MAX phases. Still, the BE of W in $\mathrm{W}_{1.33} \mathrm{CT}_{\mathrm{x}}(\mathrm{Sc})$ MXene in $0.2 \mathrm{eV}$ higher than that of $\mathrm{W}$ in $\mathrm{W}_{1.33} \mathrm{CT}_{\mathrm{x}}(\mathrm{Y})$, which might be attributed to that the former contains a larger amount of surface termination per unit formula (1.9 vs. 1.2). We suggest that at least part of the explanation may originate from a difference in reactivity of the removed elements (Sc vs Y). This remains to be further investigated.

Theoretical simulations. Theory predicts that a WC-based MXene should be a topological insulator ${ }^{34}$ or an effective catalyst. ${ }^{35}$ That is however, for the ideal $\mathrm{W}_{2} \mathrm{C}$ MXene composition 
without vacancies, and with no detailed exploration on the effect of choice of surface terminations. First principles methods based on primarily Density Functional Theory (DFT) were here used to simulate the $i$-MXene, its structure, stability, and electronic properties for various termination (T) configurations, see Methods. Due to the similar electronic structure of $\mathrm{F}$ and $\mathrm{OH}$, we chose to approximate $\mathrm{OH}$ with $\mathrm{F}$, in line with previous work. ${ }^{6,14,36}$ Furthermore, since we cannot exclude $\mathrm{OH}$ reduction during XPS analysis, with a resulting decrease in degree of surface coverage, we choose to explore a fully terminated $\mathrm{W}_{1.33} \mathrm{C}$ MXene $(x=2)$, terminated with only $\mathrm{O}, 2 \mathrm{O}: 1 \mathrm{~F}, 1 \mathrm{O}: 2 \mathrm{~F}$, and only F.

A schematic of the atomic structure along with identification of possible termination sites of $\mathrm{W}_{1.33} \mathrm{C}$ is shown in Figure $3 \mathrm{a}$. The side view shows a $\mathrm{W}_{2} \mathrm{C}$ structure but can also demonstrate the structure and termination sites of $\mathrm{W}_{1.33} \mathrm{C}$ with vacancies. The A sites are located above a metal atom in the opposite layer, the $\mathrm{T}$ sites are balanced on top of a metal atom in the closest layer, while the $\mathrm{B}$ sites are above a $\mathrm{C}$ atom. For $i$-MXene we also define $\mathrm{E}$ sites, which are located above and between two metal atoms in the closest layer. Introducing vacancies in $\mathrm{W}_{2} \mathrm{C}$ increases the size of the primitive cell and reduces the symmetry, resulting in an increased number of unique termination sites, as defined in the top view of Figure 3a. Sites with the same label (such as A1) are symmetrically equivalent, but additional apostrophe(s) are introduced for identification of unique termination configurations for mixed terminations. For details on the approach used to attain the equilibrium $i$-MXene structure, favorable terminations, and their respective sites, see Methods.

For a fully terminated surface, $\mathrm{W}_{1.33} \mathrm{CT}_{2}(\mathrm{~T}=\mathrm{O}$ and/or $\mathrm{F})$, there are three $\mathrm{O} / \mathrm{F}$ per side and primitive cell. Regardless of type of species, it was found that the only stable or metastable sites for the terminations were near the A sites (the fcc sites), slightly distorted towards the E sites and 
away from the vacancies in the closest metal layer. Structural relaxation from any start positions other than A or E indicated instability, particularly pronounced for site $\mathrm{T}$, with higher energies compared to the A site. Therefore, we can conclude that these "near-A" sites, which will be referred to as A henceforth, are the stable ones. Upon relaxation there is a slight distortion of the underlying $\mathrm{W}_{1.33} \mathrm{C}$ structure compared to the "ideal" $\mathrm{W}_{2} \mathrm{C}$, as expected due to the broken symmetry. The relaxed structure is shown in the insets of Figure 3b, however with a distortion too small to be evident from the image, but of a magnitude similar to that observed for $\mathrm{Mo}_{1.33} \mathrm{C} .{ }^{36}$ For comparison, a previous report ${ }^{34}$ as well as here performed simulations of an $\mathrm{O}$ terminated $\mathrm{W}_{2} \mathrm{C}$ show the B sites to be the most favorable ones, $1.181 \mathrm{eV} / \mathrm{f}$.u lower than the A sites, while for an $\mathrm{F}$ terminated $\mathrm{W}_{2} \mathrm{C}$, the A sites are preferred by $0.145 \mathrm{eV} /$ f.u. compared to the B sites, see Figure $\mathrm{S} 4$.

For mixed terminations of $\mathrm{O}$ and $\mathrm{F}$, we investigated the relative ratios of $1 \mathrm{O}: 2 \mathrm{~F}$ and $2 \mathrm{O}: 1 \mathrm{~F}$, for different site configurations. Given the size of the primitive cell, the $\mathrm{O}$ and $\mathrm{F}$ atoms can be organized in 9 different configurations, of which 4 are symmetrically inequivalent. For each of the two ratios, we here present the lowest energy atomic arrangement of $\mathrm{O}$ and F, even though it should be noted that several low energy configurations could be identified. For 1O:2F, the energetically most favorable configuration is denoted A1'-T2, referring to the sites of $\mathrm{O}$, with $\mathrm{F}$ occupying the remaining A sites (all terminations are in A sites). For 20:1F configurations we use the same labelling scheme, with the notation referring to the sites of the two F atoms (one per side), with the remaining four A sites being occupied by $\mathrm{O}$ (two per side). The lowest energy configuration for $2 \mathrm{O}: 1 \mathrm{~F}$ is $\mathrm{A1}$ '- $\mathrm{T1}$ ', , see selected energy curves for all termination compositions of $\mathrm{W}_{1.33} \mathrm{C}$ in Figure S7. 

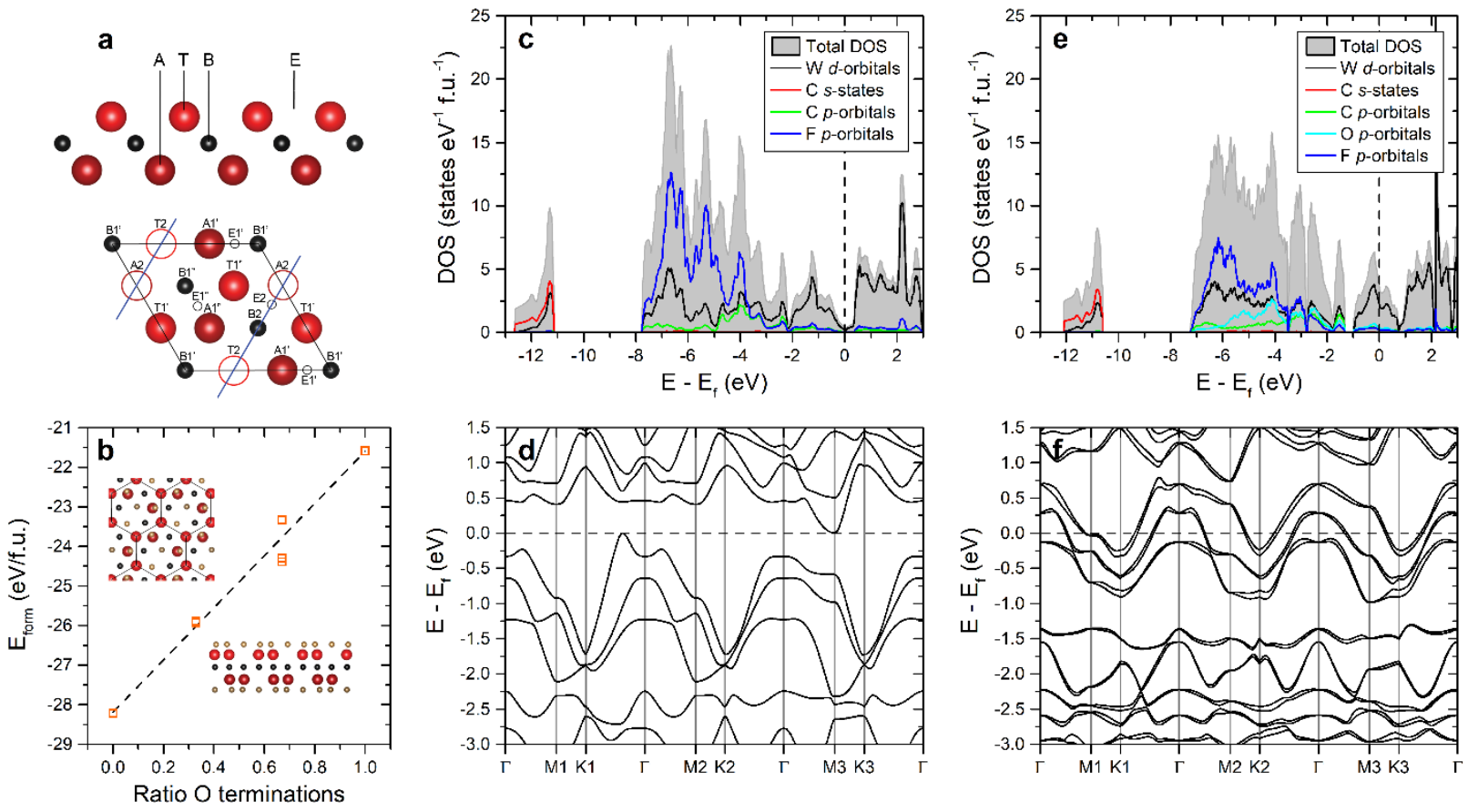

Figure 3. (a) Side view (top) and top view (bottom) of $\mathrm{W}_{1.33} \mathrm{C}$, with labels identifying termination sites $\mathrm{A}, \mathrm{B}, \mathrm{T}$ and $\mathrm{E}$. Red is $\mathrm{W}$ and black is $\mathrm{C}$. The $\mathrm{W}$ atoms in the bottom layer displayed in a darker red. The blue lines in the top view are mirror symmetry lines along the rows of vacancies. (b) Formation energy of $\mathrm{O}$ and $\mathrm{F}$ terminations on $\mathrm{W}_{1.33} \mathrm{C}$, with a straight line drawn between fully $\mathrm{O}$ and $\mathrm{F}$ terminated surfaces as a guide to the eye. The insets show a top view (top left) and a side view (bottom right) of the relaxed $\mathrm{W}_{1.33} \mathrm{C}$ structure with terminations. The terminations, $\mathrm{O}$ or $\mathrm{F}$, are brown in the figure, with a darker brown for atoms in the bottom layer. (c) Density of states of $\mathrm{F}$ terminated $\mathrm{W}_{1.33} \mathrm{C}$. (d) Band structure of $\mathrm{F}$ terminated $\mathrm{W}_{1.33} \mathrm{C}$. (e) Density of states of $\mathrm{W}_{1.33} \mathrm{C}\left(\mathrm{O}_{0.33} \mathrm{~F}_{0.67}\right)_{2}$ in $\mathrm{A} 1$ '-T2 configuration. (f) Band structure of $\mathrm{W}_{1.33} \mathrm{C}\left(\mathrm{O}_{0.33} \mathrm{~F}_{0.67}\right)_{2}$ in $\mathrm{A} 1$ ' - $\mathrm{T} 2$ configuration. The spin degeneracy has been lifted due to the Rashba effect during spin orbit coupling calculations.

Evaluation of the dynamical stability, i.e. stability with respect to lattice vibrations, was obtained by phonon calculations, see Figure $\mathrm{S} 8$, which showed that while an $\mathrm{F}$ terminated surface, $\mathrm{W}_{1.33} \mathrm{CF}_{2}$, 
can be considered stable, the $\mathrm{O}$ terminated surface, $\mathrm{W}_{1.33} \mathrm{CO}_{2}$, display a few imaginary modes, i.e. is less stable. This is in line with additional Molecular Dynamics calculations as well as comparative calculations based on density functional perturbation theory (DFPT), not shown here, which suggest that $\mathrm{W}_{1.33} \mathrm{CO}_{2}$ is clearly dynamically unstable. The phonon dispersion for the mixed configurations indicate some dynamical instability also for the oxygen-rich 2O:1F composition, while the more F-rich configuration, 10:2F, seems stable, i.e. not displaying any imaginary modes in the dispersion. The lattice parameter for the stable, lowest energy configurations are 5.203 and $5.227 \AA$ for $\mathrm{W}_{1.33} \mathrm{CF}_{2}$ and $\mathrm{W}_{1.33} \mathrm{C}\left(\mathrm{O}_{0.33} \mathrm{~F}_{0.67}\right)_{2}$, respectively.

For more insight into the stability of investigated configurations we define the formation energy $E_{\text {form }}$ of terminations on the surface of $\mathrm{W}_{1.33} \mathrm{C}$ as

$$
E_{\text {form }}=E\left(\mathrm{~W}_{1.33} \mathrm{CT}_{2}\right)-E\left(\mathrm{~W}_{1.33} \mathrm{C}\right)-(n / 2) E\left(\mathrm{~T}_{2}\right)
$$

where $E\left(\mathrm{~W}_{1.33} \mathrm{CT}_{2}\right)$ and $E\left(\mathrm{~W}_{1.33} \mathrm{C}\right)$ are the energies of the respective surface structures, $E\left(\mathrm{~T}_{2}\right)$ is the energy of a molecule of the terminating species, and $n$ is the number of terminating atoms. We note that the energy for unterminated $\mathrm{W}_{1.33} \mathrm{C}$ is imprecise given its instability, but the value can still serve as a reference for a comparison between different terminations. The results for $\mathrm{W}_{1.33} \mathrm{CT}_{2}$ is presented in Figure $3 \mathrm{~b}$ and Table S10. All evaluated termination configurations are strongly bonded to the surface, though we note distinct differences for $\mathrm{O}$ and $\mathrm{F}$ terminations. The formation energy for $\mathrm{F}$ terminations is $-28.2 \mathrm{eV} /$ formula unit (f.u.), which is significantly lower than $-21.6 \mathrm{eV} / \mathrm{f}$.u. for $\mathrm{O}$ terminations, consequently showing that $\mathrm{F}$ terminations are more strongly bonded to the surface. This is in line with previous work for the vacancy-MXene Mo. ${ }_{33} \mathrm{C},{ }^{36}$ but in contrast to calculations on the $\mathrm{Ti}_{2} \mathrm{C}$ MXene, showing a preference for $\mathrm{O}$ terminations, ${ }^{37}$ which has also been confirmed experimentally. ${ }^{38} \mathrm{In}$ addition, for $\mathrm{W}_{1.33} \mathrm{C}$, the mixed termination 
configurations end up more or less on a linear interpolation between pure $\mathrm{O}$ and pure $\mathrm{F}$ terminations.

As the electronic structure is strongly dependent on the choice of terminations, we have analyzed the termination configurations of lowest energy for all compositions, see Figure S9, with the results for the fully F-terminated surface and the F-rich 1O:2F ratio presented in Figure 3c-f. Both these configurations display a region near the Fermi level which is dominated by W d-bands, with the p-bands from the terminations becoming dominant at lower energies. However, there are distinct differences. For $\mathrm{W}_{1.33} \mathrm{CF}_{2}$, the p-bands are almost fully occupied and appear primarily between -8 and $-3 \mathrm{eV}$ with only a small amount of states above the Fermi level, see Figure $3 \mathrm{c}$ and $\mathrm{d}$. While the density of states is zero at the Fermi level there is no band gap as both valence and conduction bands touch the Fermi level, although at different points in k-space. There is also a distinct peak of $\mathrm{W}$ d-bands between -2 and $0 \mathrm{eV}$, just below the Fermi level, seen in the band structure plot as a set of three bands (6 electrons). The electronic structure of $\mathrm{W}_{1.33} \mathrm{C}\left(\mathrm{O}_{0.33} \mathrm{~F}_{0.67}\right)_{2}$ is presented in Figure $3 \mathrm{e}$ and $\mathrm{f}$. Comparing these graphs with the equivalent ones for $\mathrm{W}_{1.33} \mathrm{CF}_{2}$, the three d-bands that were just below the Fermi level for the $\mathrm{F}$ terminated surface is now between -1 and $1 \mathrm{eV}$, with the Fermi level right in the middle. This shift is due to the reduced number of electrons in the system, specifically two electrons per unit cell (one spin degenerate band). It should be noted that while we considered spin-orbit coupling for the band structure plots, it had little impact on the overall structure; there are no well-defined Dirac points to split up, and the effect is limited. However, in some of the mixed configurations, see for example Figure $3 f$, we observed lifting of the degeneracy of the spin bands due to the Rashba effect, ${ }^{39,} 40$ which occurs in $2 \mathrm{D}$ materials without inversion symmetry. As the inversion symmetry is only broken in some of the mixed configurations, it is not seen in all band structure plots. 
Comparing $\mathrm{W}_{1.33} \mathrm{CF}_{2}$ and $\mathrm{W}_{1.33} \mathrm{C}\left(\mathrm{O}_{0.33} \mathrm{~F}_{0.67}\right)_{2}$ there is also a difference in the $\mathrm{O}$ and $\mathrm{F}$ p-orbitals between -8 and $-3 \mathrm{eV}$. Of higher importance, however, is that with fewer electrons in the structure, such as in the fully $\mathrm{O}$ terminated case, there are unoccupied $\mathrm{O}$ and $\mathrm{C}$ p-bands above the fermi level, even though most p-bands are occupied and situated between -7 and $-1 \mathrm{eV}$, see Figure S9. In general terms, the $\mathrm{O}$ terminations (ideally absorbing 2 electrons) will draw a significant number of electrons from the $\mathrm{W}$ atoms. For a fully $\mathrm{O}$ terminated surface there are consequently not enough electrons available, i.e. the hybridized p-orbitals around the $\mathrm{C}$ and $\mathrm{O}$ are unfilled, along with depleted $\mathrm{W}$ d-orbitals, leaving unsatisfied bonding and the instability mentioned above. F terminations on the other hand require only 1 electron each for a full shell, and consequently the electrons available in the system may be enough to fill both the $\mathrm{F}$ and $\mathrm{C}$ orbitals and maintain stable bonding. Nonetheless, we have shown that the configuration of terminations can change the metallicity of the MXene, going from insulating/semiconducting to metallic, as shown from the obtained bandgap for O terminations only, a pseudogap with $\mathrm{F}$ terminations, and metallic bands with a termination ratio of 1O:2F.

The approximation of $\mathrm{F}$ for $\mathrm{OH}$ terminations is used for the theoretical simulations. Converting the chemical analysis from XPS using the same approximation, we find the approximate experimental ratio of $1 \mathrm{O}: 1 \mathrm{~F}$ and $1 \mathrm{O}: 2 \mathrm{~F}$ for the $\mathrm{W}_{1.33} \mathrm{CT}_{\mathrm{x}}(\mathrm{Sc})$ and $\mathrm{W}_{1.33} \mathrm{CT}_{\mathrm{x}}(\mathrm{Y})$, respectively, which is in line with theoretically predicted preferred F-rich surface composition, but still showing a compositional range suggesting a large tuning potential of the electronic properties.

\section{Electrochemical performance. The electrochemical performance of $\mathrm{W}_{1.33} \mathrm{C}(\mathrm{Sc})$ MXene} and $\mathrm{W}_{1.33} \mathrm{C}(\mathrm{Y})$ MXene is presented in Figure 4. To improve the ductility of the brittle MXene films, PEDOT:PSS polymer was mixed with the MXene in a 10:1 mass ratio. ${ }^{21}$ The films, of 
thickness $2.0 \mu \mathrm{m}\left(\mathrm{W}_{1.33} \mathrm{C}(\mathrm{Sc})\right), 3.9 \mu \mathrm{m}\left(\mathrm{W}_{1.33} \mathrm{C}(\mathrm{Sc})\right)$, and $2.5 \mu \mathrm{m}\left(\mathrm{W}_{1.33} \mathrm{C}(\mathrm{Y})\right)$, and with a density $5.3,3.5$, and $3.1 \mathrm{~g} / \mathrm{cm}^{3}$, respectively, were evaluated in a three-electrode electrochemical cell. For details of the experimental procedure, see Methods. The cyclic voltammetry (CV) plots shown in Figure 4a, 4d and Figure S10 display a deviation from a rectangular shape, indicating a pseudocapcitive contribution to the charging mechanism, which is in line with previous observations for MXenes in aqueous electrolytes, ${ }^{9}$ such as $\mathrm{Mo}_{2} \mathrm{C}$ and $\mathrm{Ti}_{3} \mathrm{C}_{2}{ }^{29,}, 41$

The normalized capacitance for a $2 \mu \mathrm{m}$ film (Figure S10) and a $3.9 \mu \mathrm{m}$ film (Figure $4 \mathrm{a}$ ) of $\mathrm{W}_{1.33} \mathrm{C}$ (Sc)-PEDOT:PSS electrodes are $610 \mathrm{~F} \mathrm{~cm}^{-3}\left(116 \mathrm{~F} \mathrm{~g}^{-1}\right)$ and $324 \mathrm{~F} \mathrm{~cm}^{-3}\left(107 \mathrm{~F} \mathrm{~g}^{-1}\right)$, respectively, at a scan rate of $5 \mathrm{mV} \mathrm{s}^{-1}$ in a $0.45 \mathrm{~V}$ voltage window. The differences in the volumetric capacitance relates to the difference in the density of the two films, which may be related to improved alignment of MXene sheets in the thinner electrode, as reported in Ref, ${ }^{42}$ but more importantly, to a different MXene-polymer distribution. For the $2 \mu \mathrm{m}$ electrode, and at slow scan rates, the current has been slightly extended at both ends of the scanning potential (Figure S10), which may be an indication of oxygen and hydrogen evolution reactions. Side reactions can result in limited ion insertion into the working electrode and imbalanced charge/discharge kinetics, with a related reduced coulombic efficiency. This is evident in Figure $4 \mathrm{~b}$ where a high coulombic efficiency is realized at increased scan rates for the $2 \mu \mathrm{m}$ film, as well as for the thicker $(3.9 \mu \mathrm{m})$ electrode. Still, up to $50 \mathrm{mV} \mathrm{s}^{-1}$ the volumetric capacitance is above $500 \mathrm{~F} \mathrm{~cm}^{-3}$, see Figure $4 \mathrm{~b}$ and Table $\mathrm{S} 11$, which altogether is significantly higher than $2 \mathrm{D}$ tungsten disulfide $\left(\mathrm{WS}_{2}\right)$ and tungsten oxide $\left(\mathrm{WO}_{3}\right)$ supercapacitors evaluated in aqueous electrolytes. ${ }^{43,44}$ A survey of previously reported $\mathrm{W}$ based materials for supercapacitors is presented in Table S12, including those improved by reinforcement of other materials. 
For comparison, the electrochemical behavior of $\mathrm{W}_{1.33} \mathrm{C}(\mathrm{Y})$-PEDOT:PSS electrode of $2.5 \mu \mathrm{m}$ thickness (density of $3.1 \mathrm{~g} / \mathrm{cm}^{3}$ ) was also investigated. The CV plots in Figure 4 d gives a volumetric capacitances of $591 \mathrm{~F} \mathrm{~cm}^{-3}$, and a gravimetric capacitance of $191 \mathrm{~F} \mathrm{~g}^{-1}$, at $5 \mathrm{mV} \mathrm{s}^{-1}$. All capacitance values are summarized in Table S11.

Galvanostatic charge/discharge tests were also performed at current densities of 1, 3, 5, and 10 $\mathrm{A} \mathrm{g}^{-1}$, see Figure S11. The curves have a close to symmetric triangular profile. Moreover, after applying a current density of $10 \mathrm{~A} \mathrm{~g}^{-1}$ for 10000 cycles, see Figure $4 \mathrm{c}$ and $4 \mathrm{f}$, the films displayed a high stability with a retention around 85\%. Furthermore, the Nyquist plot in Figure S12 shows a liner behavior and a low equivalent series resistance for both electrode materials. Comparing the results from the electrochemical testing of $\mathrm{W}_{1.33} \mathrm{C}(\mathrm{Y})$ and $\mathrm{W}_{1.33} \mathrm{C}(\mathrm{Sc})$ containing electrodes of similar thickness and density, a higher capacitance is obtained for the $\mathrm{W}_{1.33} \mathrm{C}(\mathrm{Y})$-PEDOT:PSS film. The reason thereof requires a study focused on electrochemical behavior, though it can be noted that a similar conductivity (see below) suggest an influence of the higher amount of surface terminations as well as a higher relative $\mathrm{F}$ concentration for the $\mathrm{W}_{1.33} \mathrm{C}(\mathrm{Y})$ containing material.

Although the potential for supercapacitor applications is high for the here analyzed MXene compared to other W-based materials to date, other MXenes have displayed higher capacitance. ${ }^{9}$ ${ }^{42}$ It should be noted, however, that the potential for improvement considering further optimization of the precursor i-MAX phase, the etching conditions, surface terminations, and the structure of the assembled MXene film is very high. It is also well established that the W-C bond is very strong. Hence, the interest in W-based materials for the MXene community is motivated by potentially superior mechanical properties, suggesting advantages also as addition in composite (electrode) materials . Moreover, the conductivity of the tested electrodes is $0.1-0.15 \mathrm{~S} \mathrm{~cm}^{-1}$, which is higher than for e.g. $\mathrm{WO}_{3}\left(0.01 \mathrm{~S} \mathrm{~cm}^{-1}\right)$ and $\mathrm{WS}_{2}\left(0.002 \mathrm{~S} \mathrm{~cm}^{-1}\right){ }^{45,}{ }^{46}$ Considering that tungsten carbide 
(WC) has a very high melting point $\left(2776^{\circ} \mathrm{C}\right.$ ), a high Youngs Modulus (707 GPa), a high catalytic efficiency and chemical stability, further investigations in this direction are encouraged.
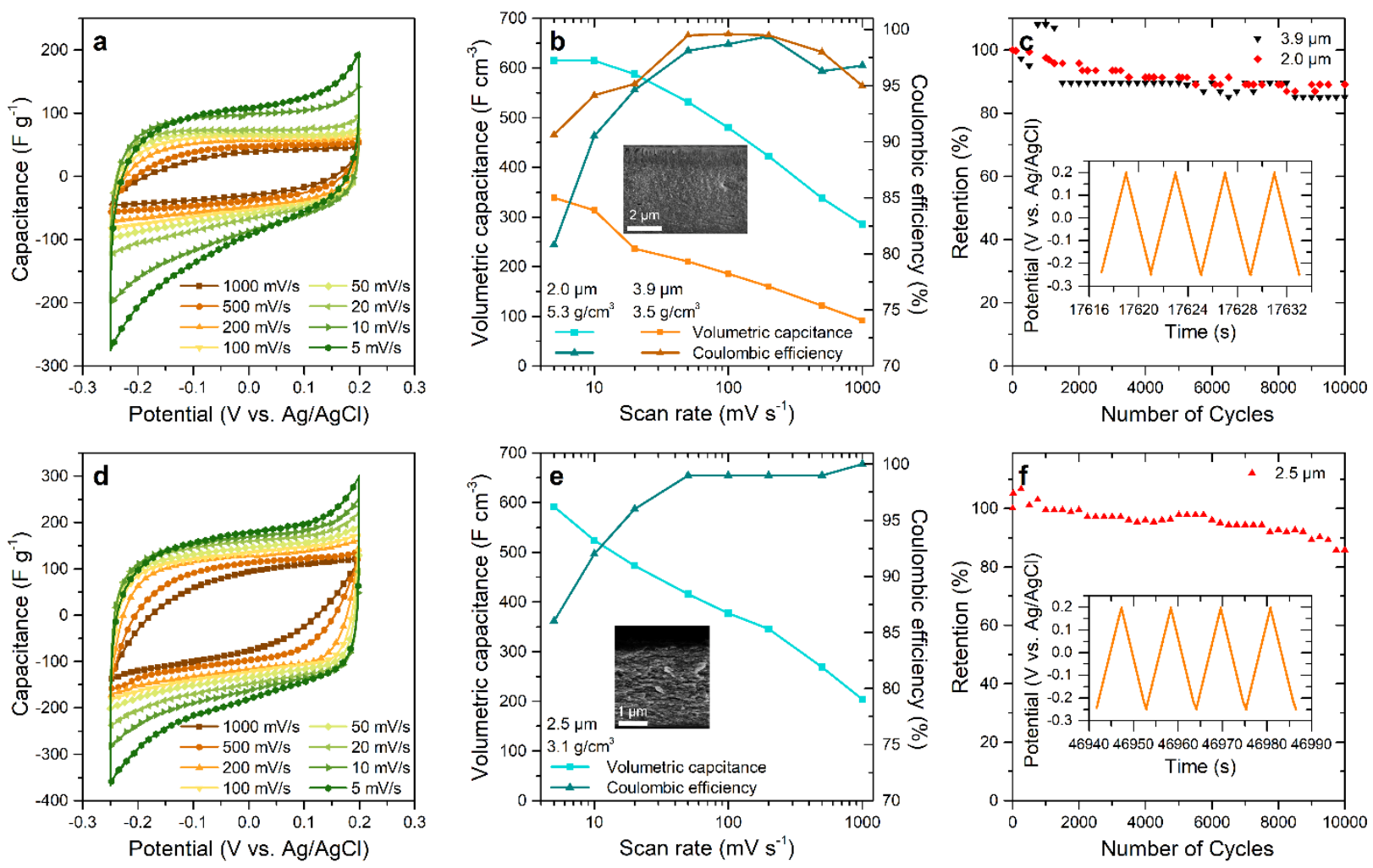

Figure 4. (a) $\mathrm{CV}$ curves for a $3.9 \mu \mathrm{m} \mathrm{W} \mathrm{W}_{1.33} \mathrm{C}$ (Sc)-PEDOT:PSS electrode measured at 5 to 1000 $\mathrm{mV} \mathrm{s}^{-1}$ scan rate in $1 \mathrm{M} \mathrm{H}_{2} \mathrm{SO}_{4}$. (b) Calculated volumetric capacitance (left axis) and the coulombic efficiency (right axis) for the $3.9 \mu$ m electrode, and a $2.0 \mu \mathrm{m}$ electrode (see Supporting Figure 10). The inset shows a cross section of the $3.9 \mu \mathrm{m}$ electrode . (c) Capacitance retention (stability) test up to 10000 cycles at $10 \mathrm{~A} \mathrm{~g}^{-1}$ current density for the $3.9 \mu \mathrm{m}$ electrode and the $2.0 \mu \mathrm{m}$ electrode. (d) $\mathrm{CV}$ curves for a $2.5 \mu \mathrm{m} \mathrm{W} 1.33 \mathrm{C}$ (Y)-PEDOT:PSS electrode measured at 5 to $1000 \mathrm{mV} \mathrm{s}^{-1}$ scan rate in $1 \mathrm{M} \mathrm{H}_{2} \mathrm{SO}_{4}$. (e) Calculated volumetric capacitance (left axis) and the coulombic efficiency (right axis). The inset shows a cross section of the $2.5 \mu \mathrm{m}$ electrode. (f) Capacitance retention (stability) test up to 10000 cycles at $10 \mathrm{~A} \mathrm{~g}^{-1}$ current density for the $2.5 \mu \mathrm{m}$ electrode. 


\section{CONCLUSIONS}

In conclusion, we have synthesized $\mathrm{W}_{1.33} \mathrm{C}$ MXene from the $i$-MAX phases $\left(\mathrm{W}_{2 / 3} \mathrm{Sc}_{1 / 3}\right)_{2} \mathrm{AlC}$ and $\left(\mathrm{W}_{2 / 3} \mathrm{Y}_{1 / 3}\right)_{2} \mathrm{AlC}$, and have performed complete chemical characterization based on XPS. It is shown that the same MXene from two different parent materials display different surface composition, with the amount of $-\mathrm{O}$ and $-\mathrm{OH}$ terminations after etching of $\mathrm{Al}$ and $\mathrm{Sc}$ is more than double that of $-\mathrm{F}$ terminations, while after etching $\mathrm{Al}$ and $\mathrm{Y}$ the amounts of $-\mathrm{O},-\mathrm{OH}$ and $-\mathrm{F}$ terminations are equal. The XPS results are correlated to theoretical simulations of the W-based MXenes terminated with $\mathrm{F}$, $\mathrm{O}$, or a mixture thereof (using the approximation of $\mathrm{F}$ for $\mathrm{OH}$ ), which show indications of a preferred F-rich termination content, in line with the XPS analysis. Furthermore, MXene functionalization through control of surface terminations is predicted from a metallicity of the MXene going from insulating/semiconducting to metallic, as shown from the obtained bandgap for $\mathrm{O}$ terminations only, a pseudogap with $\mathrm{F}$ terminations, and metallic bands with a termination ratio of 10:2F. Altogether the theoretical analysis together with the experimentally shown range of surface terminations suggest a wide range of attainable properties. Additionally, free-standing films of $\mathrm{W}_{1.33} \mathrm{C}$ mixed with a small amount of polymer (PEDOT:PSS) were tested as electrodes in supercapacitors, showing capacitances around $600 \mathrm{~F} \mathrm{~cm}^{-3}$ in $1 \mathrm{M} \mathrm{H}_{2} \mathrm{SO}_{4}$ and high stability, which is better than other known W-based 2D materials to date. Further work on these materials is encouraged, considering, e.g., expected strong W-C bonds and high catalytic efficiency.

\section{METHOD}

Computational details. Total energies, density of states and band structures were calculated from first principles using Density Functional Theory (DFT) in the Vienna ab-initio Simulation Package (VASP) software. ${ }^{47,} 48$ The exchange-correlation effects were treated within the generalized gradient approximation (GGA) of Perdew-Burke-Ernzerhof. ${ }^{49}$ Spin orbit coupling 
(SOC) was taken into account for evaluation of band structures. The cutoff energy for plane-wave expansion was $400 \mathrm{eV}$. K-point sampling was adjusted depending on the supercell size to ensure an accuracy of at least $0.1 \mathrm{meV} /$ atom during structural relaxations. Accordingly, a 15x15x1 mesh was used during relaxation of $1 \mathrm{x} 1 \mathrm{~W}_{4} \mathrm{C}_{3}$ supercell size. Larger meshes were used for accurate calculation of density of states and band structure, once a relaxed structure had been determined. A total supercell height of $42 \AA$ was used to avoid self-interaction between MXene sheets across the periodic boundaries. With a total MXene sheet thickness right below $5 \AA$, the vacuum spacing is approximately $37 \AA$.

For evaluation of dynamical stability, we used molecular dynamics (MD) simulations and combined those with the MD based temperature dependent effective potential (TDEP) method in order to obtain force constants from which the phonon dispersions were determined. ${ }^{50,51}$ For the MD calculations, we used a $4 \times 4$ in-plane sized supercell, with a total of 208 atoms with full terminations. Temperature was set at $300 \mathrm{~K}$ and the calculations ran for around 3000 timesteps, or about six ps. Electronic self-consistency within the MD simulations were determined at the $\Gamma$-point only. We also performed selected phonon calculations with density functional perturbation theory (DFPT) ${ }^{52}$ using both Quantum Espresso $(\mathrm{QE})^{53}$ and VASP for comparison.

The symmetry of these ordered $i$-MXene structures is reduced with respect to the hexagonal symmetry of $\mathrm{M}_{2} \mathrm{C} . \mathrm{M}_{2} \mathrm{C}$ has a 6-fold rotational invariance, while the symmetry of $\mathrm{M}_{1.33} \mathrm{C}$ is only 2-fold. As such, when presenting band structure diagrams for these structures, both for electron and phonon dispersions, we have to expand the definition of symmetry points of the hexagonal Brillouin zone (BZ), as originally presented in $\operatorname{Ref}^{34}$, and as shown in Figure S5.

The equilibrium $i$-MXene structure, favorable terminations and their respective sites, were identified by positioning surface species in different configurations on sites A, B, T and E (Fig. 
3a), followed by relaxation of the internal atomic structure while keeping the cell shape and size fixed, and then repeating these calculations for multiple in-plane lattice parameters. This gives the equilibrium lattice parameter and energy for each termination configuration through the use of a modified Morse equation of state. ${ }^{54}$ Prior to evaluation of surface terminations, a clean $\mathrm{W}_{1.33} \mathrm{C}$ was simulated, and was found to be unstable. For further details, see Supplemental information. Visualization of atomic structures herein was done with the VESTA code..$^{55}$

$i$-MAX synthesis. Elemental powders of W (12 $\mu \mathrm{m}$, Sigma-Aldrich), Sc (-200 mesh Stanford Advanced Material), Al (-325 mesh Alfa Aesar) )and graphite (-200 mesh Alfa Aesar), were mixed in desired stoichiometric ratios and placed in a covered $\mathrm{Al}_{2} \mathrm{O}_{3}$ crucible. The latter was placed in an alumina tube furnace - through which Ar was flowing - heated at a rate of $8^{\circ} \mathrm{C}$ per min to 1450 ${ }^{\circ} \mathrm{C}$ and held at that temperature for $2 \mathrm{~h}$. After cooling, the lightly sintered sample was crushed in an agate mortar, resulting in a fine $\left(\mathrm{W}_{2 / 3} \mathrm{Sc}_{1 / 3}\right)_{2} \mathrm{AlC}$ powder. A similar procedure was carried out for the synthesis of $\left(\mathrm{W}_{2 / 3} \mathrm{Y}_{1 / 3}\right)_{2} \mathrm{AlC}$, where the same $\mathrm{W}, \mathrm{Al}$ and graphite powders together with elemental Y powders (with a particle size of -40 mesh, Sigma-Aldrich) were mixed and sintered at $1450^{\circ} \mathrm{C}$ for $2 \mathrm{~h}$.

MXene synthesis. MXene samples were synthesized by adding $4 \mathrm{~g}$ of $i$-MAX powders was added to $80 \mathrm{ml} 48 \%$ aqueous hydrofluoric acid, HF (Honeywell Fluka), and stirred using a Teflon coated magnetic stirrer for $35 \mathrm{~h}$ at room temperature. Afterwards, the mixture was washed with $\mathrm{N}_{2}$ deaerated water. Washing was done by adding $100 \mathrm{ml}$ of distilled (DI), deaerated water to the etched powder then shaking manually for $30 \mathrm{~s}$ then centrifuging at $5000 \mathrm{rpm}$ for $1 \mathrm{~min}$. This process was repeated till the mixture $\mathrm{pH}$ was $\approx 5-6$.

The produced multilayered MXene was delaminated via intercalation by adding $4 \mathrm{~g}$ of the powder into $20 \mathrm{ml}$ of $50 \mathrm{vol} \%$ tetrabutylammonium hydroxide (TBAOH) (Sigma Aldrich) at room 
temperature, which was afterwards shook manually for $5 \mathrm{~min}$. The solution was centrifuged for another $5 \mathrm{~min}$ at $5000 \mathrm{rpm}$ and the supernatant was decanted. Afterwards, the sediment was washed by DI deaerated water three times without shaking in order to remove any $\mathrm{TBAOH}$ residues, each time using $50 \mathrm{ml}$ of DI deaerated water. Finally, the intercalated $4 \mathrm{~g}$ of the MXene powders was mixed with $50 \mathrm{ml}$ of DI deaerated water, manually shaken for $5 \mathrm{~min}$ then centrifuged at $3000 \mathrm{rpm}$ for $1 \mathrm{~h}$. The supernatant was taken for further analysis and characterization.

For XPS analysis, delaminated free-standing films of $\mathrm{W}_{1.33} \mathrm{CT}_{\mathrm{x}}$, obtained from both $\left(\mathrm{W}_{2 / 3} \mathrm{Sc}_{1 / 3}\right)_{2} \mathrm{AlC}$ and $\left(\mathrm{W}_{2 / 3} \mathrm{Y}_{1 / 3}\right)_{2} \mathrm{AlC} i$-MAX phases were made by vacuum filtration of $20 \mathrm{ml}$ of the supernatant mentioned above through a nanoporous polypropylene membrane (3501 coated PP, $0.064 \mu \mathrm{m}$ pore size, Celgard, USA). The overall air exposure time after filtering and before XPS analysis was less than $30 \mathrm{~min}$. The samples were fixed on the sample holder using a doublesided tape and grounded using copper rod which connected the sample holder to the top of the sample. No Ar sputtering was done before the XPS measurements.

For electrochemical characterization, composite electrodes were prepared by mixing the supernatant of $\mathrm{W}_{1.33} \mathrm{C}$ delaminated flakes from $\left(\mathrm{W}_{2 / 3} \mathrm{Sc}_{1 / 3}\right)_{2} \mathrm{AlC}$ and $\left(\mathrm{W}_{2 / 3} \mathrm{Y}_{1 / 3}\right)_{2} \mathrm{AlC}$ in water with PEDO:PSS, PH1000 with ratio of 10:1 by mass. The mixture was manually shaken for $5 \mathrm{~min}$ before filtering through the nanoporous polypropylene Celgard membrane, forming a $\sim 2 \mu \mathrm{m}$ thick freestanding film.

Structural and chemical characterization. XRD measurements were performed on a PANalytical X'Pert powder diffractometer equipped with a $\mathrm{Cu}-\mathrm{K}_{\alpha}$ radiation source. A graded Bragg-Brentano HD with a $1 / 4^{\circ}$ divergent and $1 / 2^{\circ}$ anti-scattered slits in the incident beam side, and a $5 \mathrm{~mm}$ anti-scatter slit together with a Soller slit (with an opening rad. of 0.04), in the diffracted beam side were utilized for these measurements. A continuous scan from $0^{\circ}$ to $100^{\circ}$ was 
performed on the sample using a step size of $0.08^{\circ}$ with a $5.7 \mathrm{~s}$ time per step. High resolution scanning transmission electron microscopy (HRSTEM) was performed in the double-corrected Linköping FEI Titan ${ }^{3}$ 60-300, operated at 300 kV. High-angle annular dark field (HAADF) images were acquired using a beam semi convergence angle of $20 \mathrm{mrad}$ and a camera length of $185 \mathrm{~mm}$ with a pixel dwell time of 15 us.

XPS measurements were performed on cold pressed discs of $i$-MAX phases of $\left(\mathrm{W}_{2 / 3} \mathrm{Sc}_{1 / 3}\right)_{2} \mathrm{AlC}$ and $\left(\mathrm{W}_{2 / 3} \mathrm{Y}_{1 / 3}\right)_{2} \mathrm{AlC}$ and free-standing $d-\mathrm{W}_{1.33} \mathrm{C}(\mathrm{Sc})$ and $d-\mathrm{W}_{1.33} \mathrm{C}(\mathrm{Y})$ films using a surface analysis system (Kratos AXIS Ultra ${ }^{\text {DLD }}$, Manchester, U.K.) using monochromatic Al-Ka (1486.6 $\mathrm{eV}$ ) radiation. The $\mathrm{X}$-ray beam irradiated the surface of the sample at an angle of $45^{\circ}$, with respect to the surface and provided an X-ray spot of $300 \times 800 \mu \mathrm{m}$. Charge neutralization was performed using a co-axial, low energy $(\sim 0.1 \mathrm{eV})$ electron flood source to avoid shifts in the recorded binding energy, BE. XPS spectra were recorded for F 1s, O 1s, C 1s, Al 2p, and W 4f. Scandium, and Nitrogen were unable to be determined due to the overlap of their regions scandium Sc $2 p$, nitrogen $\mathrm{N}$ 1s region (nitrogen originates from the intercalation of $\mathrm{W}_{1.33} \mathrm{C}$ with tetrabutyl ammonium hydroxide which is used for delamination), and Y 3s region, see Figure S4a and b. The analyzer pass energy used for all the regions was $20 \mathrm{eV}$ with a step size of $0.1 \mathrm{eV}$. The BE scale of all XPS spectra was referenced to the Fermi-edge $\left(E_{F}\right)$, which was set to a $\mathrm{BE}$ of zero $\mathrm{eV}$. The peak fitting was carried out using CasaXPS Version 2.3.16 RP 1.6 in the same manner as in Ref. ${ }^{28,29,56}$. While the global elemental percentage was quantified as in Ref. 56.

Electrochemical analysis. The composite electrodes were prepared by mixing the supernatant of $\mathrm{W}_{1.33} \mathrm{C}$ delaminated flakes from $\left(\mathrm{W}_{2 / 3} \mathrm{Sc}_{1 / 3}\right)_{2} \mathrm{AlC}$ and $\left(\mathrm{W}_{2 / 3} \mathrm{Y}_{1 / 3}\right)_{2} \mathrm{AlC}$ in water with PEDOT:PSS, PH1000 supplied by Hareus Deutschaland GmbH with a ratio of 10:1 by mass. The mixture was manually shaken for 5 min before filtering through the nanoporous polypropylene 
Celgard membrane, forming thick freestanding films of thickness $2.0,3.9$, and $2.5 \mu \mathrm{m}$, and with a density of $5.3,3.5$, and $3.1 \mathrm{~g} / \mathrm{cm}^{3}$, respectively. A difference between the higher density film and the other two films is filtering made from a solution of higher MXene concentration in the first case. A Jandel RM3000 Four-point probe was used to estimate the conductivity of the $\mathrm{W}_{1.33} \mathrm{C}$ PEDOT:PSS electrodes. The electrochemical test was performed using a Biologic VP3 potentiostat and a Swagelock cell in a three-electrode configuration. The reference electrode was $\mathrm{Ag} / \mathrm{AgCl}$ immersed in $1 \mathrm{MKCl}$, and a platinum disk on the counter electrode side and gold disk on the other side served as current collectors. The circular Celgard 3501 polypropylene was used as separator. The test medium was $1 \mathrm{M} \mathrm{H}_{2} \mathrm{SO}_{4}$, for which precyclic $\mathrm{CV}$ was performed at $20 \mathrm{mV} \mathrm{s}^{-1}$ for 50 cycles before the $\mathrm{CV}$ test, recorded for a scanning potential between 0 and $0.45 \mathrm{~V}$ at different scan rates $\left(5-1000 \mathrm{mV} \mathrm{s}^{-1}\right)$. The precycling was performed to ensure that the electrodes are well saturated with electrolyte and that the $\mathrm{CV}$ profiles are stabilized, see $\mathrm{CV}$-curves from before and after precycling in Fig. S13. The gravimetric capacitance (Cs) was calculated based on equation 1,

$$
C s=\frac{1}{m \Delta V} \int_{E 1}^{E 2} \frac{I}{v} d E,
$$

where $\mathrm{m}$ is the mass of working electrode, $\Delta \mathrm{V}$ is the voltage window, $\mathrm{E} 1$ and $\mathrm{E} 2$ are the voltage limits, $\mathrm{I}$ is the measured current and $\mathrm{v}$ is the scan rate. The voltage window presented in Fig. 4a and $\mathrm{d}(0.45 \mathrm{~V})$ can be compared to the stable electrochemical window also for an increased voltage window $(0.5 \mathrm{~V})$ at a scan rate of $20 \mathrm{mV} / \mathrm{s}$, as shown in Fig. S14. The volumetric capacitance was calculated by multiplying the gravimetric capacitance by the electrode density $\left(5.3 \mathrm{~g} \mathrm{~cm}^{-3}\right)$. Electrochemical impedance test (EIS) was measured at frequency ranges from $100 \mathrm{mHz}$ to 100 $\mathrm{kHz}$ at potential amplitude of $10 \mathrm{mV}$.

\section{ASSOCIATED CONTENT}


Supporting Information. The Supporting Information is available free of charge on the ACS Publications website at DOI:

XRD diffractograms and SEM images of i-MAX phases and corresponding MXenes; additional XPS spectra of $i$-MAX phases and corresponding MXenes along with Tables with XPS fitting results; calculated energy curves, formation energies, phonon dispersion, electronic density oft states and band structure for various MXene termination, additional electrochemical characterization of MXenes (PDF)

\section{AUTHOR INFORMATION}

\section{Corresponding Authors}

*E-mail: johanna.rosen@liu.se

ORCHID

Martin Dahlqvist 0000-0001-5036-2833

\section{Author Contributions}

The manuscript was written through contributions of all authors. All authors have given approval to the final version of the manuscript.

\section{ACKNOWLEDGMENT}

J.R. and P.P. acknowledge support from the Swedish Foundation for Strategic Research (SSF) for Project Funding (EM16-0004) and the Research Infrastructure Fellow program no. RIF 14-0074, from the Knut and Alice Wallenberg (KAW) Foundation for a Fellowship Grant, Project funding (KAW 2015.0043), and for support to the Linköping Ultra Electron Microscopy Laboratory, and from the Swedish Government Strategic Research Area in Materials Science on Functional Materials at Linköping University (Faculty Grant SFO-Mat-LiU No 2009 00971). The Swedish 
Research council is gratefully acknowledged through Project 642-2013-8020 and 2016-04412. The calculations were carried out using supercomputer resources provided by the Swedish National Infrastructure for Computing (SNIC) at the National Supercomputer Centre (NSC), the High Performance Computing Center North (HPC2N), and the PDC Center for High Performance Computing. 


\section{REFERENCES}

1. Novoselov, K. S.; Geim, A. K.; Morozov, S. V.; Jiang, D.; Zhang, Y.; Dubonos, S. V.;

Grigorieva, I. V.; Firsov, A. A., Electric Field Effect in Atomically Thin Carbon Films. Science 2004, 306 (5696), 666-669.

2. Ci, L.; Song, L.; Jin, C.; Jariwala, D.; Wu, D.; Li, Y.; Srivastava, A.; Wang, Z. F.; Storr, K.; Balicas, L.; Liu, F.; Ajayan, P. M., Atomic layers of hybridized boron nitride and graphene domains. Nat. Mater. 2010, 9, 430.

3. Hinnemann, B.; Moses, P. G.; Bonde, J.; Jørgensen, K. P.; Nielsen, J. H.; Horch, S.; Chorkendorff, I.; Nørskov, J. K., Biomimetic Hydrogen Evolution: $\mathrm{MoS}_{2}$ Nanoparticles as Catalyst for Hydrogen Evolution. J. Am. Chem. Soc. 2005, 127 (15), 5308-5309.

4. Voiry, D.; Yamaguchi, H.; Li, J.; Silva, R.; Alves, D. C. B.; Fujita, T.; Chen, M.; Asefa, T.; Shenoy, V. B.; Eda, G.; Chhowalla, M., Enhanced catalytic activity in strained chemically exfoliated $\mathrm{WS}_{2}$ nanosheets for hydrogen evolution. Nat. Mater. 2013, 12, 850.

5. Allain, A.; Kis, A., Electron and Hole Mobilities in Single-Layer WSe 2 . ACS Nano 2014, $8(7), 7180-7185$.

6. Naguib, M.; Kurtoglu, M.; Presser, V.; Lu, J.; Niu, J.; Heon, M.; Hultman, L.; Gogotsi, Y.; Barsoum, M. W., Two-dimensional nanocrystals produced by exfoliation of $\mathrm{Ti}_{3} \mathrm{AlC}_{2}$. Adv. Mater. 2011, 23 (37), 4248-4253.

7. Naguib, M.; Mashtalir, O.; Carle, J.; Presser, V.; Lu, J.; Hultman, L.; Gogotsi, Y.; Barsoum, M. W., Two-Dimensional Transition Metal Carbides. ACS Nano 2012, 6 (2), 1322-1331.

8. Barsoum, M. W., MAX Phases, Properties of Machinable Ternary Carbides and Nitrides. Wiley: New York, 2013. 
9. Anasori, B.; Lukatskaya, M. R.; Gogotsi, Y., 2D metal carbides and nitrides (MXenes) for energy storage. Nat. Rev. Mater. 2017, 2, 16098.

10. Naguib, M.; Come, J.; Dyatkin, B.; Presser, V.; Taberna, P.-L.; Simon, P.; Barsoum, M. W.; Gogotsi, Y., MXene: a promising transition metal carbide anode for lithium-ion batteries. Electrochem. Commun. 2012, 16 (1), 61-64.

11. Ghidiu, M.; Lukatskaya, M. R.; Zhao, M.-Q.; Gogotsi, Y.; Barsoum, M. W., Conductive two-dimensional titanium carbide 'clay' with high volumetric capacitance. Nature 2014, 516 (7529), 78-81.

12. Tao, Q.; Dahlqvist, M.; Lu, J.; Kota, S.; Meshkian, R.; Halim, J.; Palisaitis, J.; Hultman, L.; Barsoum, M. W.; Persson, P. O. Å.; Rosen, J., Two-dimensional Mo1.33 C MXene with divacancy ordering prepared from parent 3D laminate with in-plane chemical ordering. Nat. Commun. 2017, 8, 14949.

13. Shahzad, F.; Alhabeb, M.; Hatter, C. B.; Anasori, B.; Man Hong, S.; Koo, C. M.; Gogotsi, Y., Electromagnetic interference shielding with 2D transition metal carbides (MXenes). Science 2016, 353 (6304), 1137-1140.

14. Khazaei, M.; Arai, M.; Sasaki, T.; Chung, C.-Y.; Venkataramanan, N. S.; Estili, M.; Sakka, Y.; Kawazoe, Y., Novel Electronic and Magnetic Properties of Two-Dimensional Transition Metal Carbides and Nitrides. Adv. Funct. Mater. 2013, 23 (17), 2185-2192.

15. Fashandi, H.; Ivády, V.; Eklund, P.; Spetz, A. L.; Katsnelson, M. I.; Abrikosov, I. A., Dirac points with giant spin-orbit splitting in the electronic structure of two-dimensional transition-metal carbides. Phys. Rev. B 2015, 92 (15), 155142. 
16. Liu, Z.; Wu, E.; Wang, J.; Qian, Y.; Xiang, H.; Li, X.; Jin, Q.; Sun, G.; Chen, X.; Wang, J.; Li, M., Crystal structure and formation mechanism of $\left(\mathrm{Cr}_{2 / 3} \mathrm{Ti}_{1 / 3}\right)_{3} \mathrm{AlC}_{2} \mathrm{MAX}$ phase. Acta Mater. 2014, 73 (0), 186-193.

17. Anasori, B.; Xie, Y.; Beidaghi, M.; Lu, J.; Hosler, B. C.; Hultman, L.; Kent, P. R. C.; Gogotsi, Y.; Barsoum, M. W., Two-dimensional, ordered, double transition metals carbides (MXenes). ACS Nano 2015, 9 (10), 9507-9516.

18. Meshkian, R.; Tao, Q.; Dahlqvist, M.; Lu, J.; Hultman, L.; Rosen, J., Theoretical stability and materials synthesis of a chemically ordered MAX phase, $\mathrm{Mo}_{2} \mathrm{ScAlC}_{2}$, and its two-dimensional derivate $\mathrm{Mo}_{2} \mathrm{ScC}_{2}$ MXene. Acta Mater. 2017, 125, 476-480.

19. Dahlqvist, M.; Lu, J.; Meshkian, R.; Tao, Q.; Hultman, L.; Rosen, J., Prediction and synthesis of a family of atomic laminate phases with Kagomé-like and in-plane chemical ordering. Sci. Adv. 2017, 3 (7), e1700642.

20. Persson, I.; Ghazaly, A. e.; Tao, Q.; Halim, J.; Kota, S.; Darakchieva, V.; Palisaitis, J.; Barsoum, M. W.; Rosen, J.; Persson, P. O. Å., Tailoring Structure, Composition, and Energy Storage Properties of MXenes from Selective Etching of In-Plane, Chemically Ordered MAX Phases. Small 2018, 14, 1703676.

21. Qin, L.; Tao, Q.; El Ghazaly, A.; Fernandez-Rodriguez, J.; Persson, P. O. Å.; Rosen, J.; Zhang, F., High-Performance Ultrathin Flexible Solid-State Supercapacitors Based on Solution Processable Mo ${ }_{1.33}$ C MXene and PEDOT:PSS. Adv. Funct. Mater. 2018, 28 (2), 1703808.

22. Meshkian, R.; Dahlqvist, M.; Lu, J.; Wickman, B.; Halim, J.; Thörnberg, J.; Tao, Q.; Li, S.; Intikhab, S.; Snyder, J.; Barsoum, M. W.; Yildizhan, M.; Palisaitis, J.; Hultman, L.; Persson, P. O. Å.; Rosen, J., W-based atomic laminates and their $2 \mathrm{D}$ derivative $\mathrm{W}_{1.33} \mathrm{C}$ MXene with vacancy ordering. Adv. Mater. 2018, 30, 1706409. 
23. Sevy, A.; Huffaker, R. F.; Morse, M. D., Bond Dissociation Energies of Tungsten Molecules: WC, WSi, WS, WSe, and WCl. The Journal of Physical Chemistry A 2017, 121 (49), 9446-9457.

24. Fleisch, T. H.; Mains, G. J., An XPS study of the UV reduction and photochromism of $\mathrm{MoO}_{3}$ and $\mathrm{WO}_{3}$. The Journal of Chemical Physics 1982, 76 (2), 780-786.

25. Weigert, E. C.; Esposito, D. V.; Chen, J. G., Cyclic voltammetry and X-ray photoelectron spectroscopy studies of electrochemical stability of clean and Pt-modified tungsten and molybdenum carbide (WC and $\mathrm{Mo}_{2} \mathrm{C}$ ) electrocatalysts. Journal of Power Sources 2009, 193 (2), 501-506.

26. Bensaoula, A.; Grossman, E.; Ignatiev, A., Etching of tungsten with $\mathrm{XeF}_{2}$ : An x-ray photoelectron spectroscopy study. J. Appl. Phys. 1987, 62 (11), 4587-4590.

27. Chen, W.; Roberts, J. T., Adsorption and reaction of $\mathrm{WF}_{6}$ on W(100). Surface Science 1995, 324 (2), 169-184.

28. Halim, J.; Cook, K. M.; Naguib, M.; Eklund, P.; Gogotsi, Y.; Rosen, J.; Barsoum, M. W., X-ray photoelectron spectroscopy of select multi-layered transition metal carbides (MXenes). Applied Surface Science 2016, 362, 406-417.

29. Halim, J.; Kota, S.; Lukatskaya, M. R.; Naguib, M.; Zhao, M.-Q.; Moon, E. J.; Pitock, J.; Nanda, J.; May, S. J.; Gogotsi, Y.; Barsoum, M. W., Synthesis and Characterization of 2D Molybdenum Carbide (MXene). Adv. Funct. Mater. 2016, 26 (18), 3118-3127.

30. Halim, J. An X-Ray Photoelectron Spectroscopy Study of Multilayered Transition Metal Carbides (Mxenes). Drexel University, 2016.

31. Mesarwi, A.; Ignatiev, A., Interaction of $Y$ overlayers with the GaAs(100) surface and oxidation of the Y/GaAs interface. Surface Science 1993, 282 (3), 371-379. 
32. Vasquez, R. P.; Foote, M. C.; Hunt, B. D., Reaction of nonaqueous halogen solutions with $\mathrm{YBa}_{2} \mathrm{Cu}_{3} \mathrm{O}_{7-x} . J$. Appl. Phys. 1989, 66 (10), 4866-4877.

33. Karlsson, L. H.; Birch, J.; Halim, J.; Barsoum, M. W.; Persson, P. O. Å., Atomically Resolved Structural and Chemical Investigation of Single MXene Sheets. Nano Lett. 2015, 15 (8), 4955-4960.

34. Weng, H.; Ranjbar, A.; Liang, Y.; Song, Z.; Khazaei, M.; Yunoki, S.; Arai, M.; Kawazoe, Y.; Fang, Z.; Dai, X., Large-gap two-dimensional topological insulator in oxygen functionalized MXene. Phys. Rev. B 2015, 92 (7), 075436.

35. Pan, H., Ultra-high electrochemical catalytic activity of MXenes. Sci. Rep. 2016, 6, 32531.

36. Lind, H.; Halim, J.; Simak, S. I.; Rosen, J., Investigation of vacancy-ordered Mo1.33C MXene from first principles and x-ray photoelectron spectroscopy. Phys. Rev. Mater. 2017, 1 (4), 044002 .

37. Ashton, M.; Mathew, K.; Hennig, R. G.; Sinnott, S. B., Predicted Surface Composition and Thermodynamic Stability of MXenes in Solution. J. Phys. Chem. C 2016, 120 (6), 3550-3556.

38. Ingemar, P.; Lars-Åke, N.; Joseph, H.; Michel, W. B.; Vanya, D.; Justinas, P.; Johanna, R.; Per, O. A. P., On the organization and thermal behavior of functional groups on $\mathrm{Ti}_{3} \mathrm{C}_{2} \mathrm{MXene}$ surfaces in vacuum. 2D Materials 2018, 5 (1), 015002.

39. Rashba, E. I., Symmetry of energy bands in crystals of wurtzite type: I. symmetry of bands disregarding spin-orbit interaction. Sov. Phys.-Solid State 1959, 1, 368-80.

40. Rashba, E. I.; Sheka, V. I., Symmetry of energy bands in crystals of wurtzite type: II. Symmetry of bands including spin-orbit interaction. Fiz. Tverd. Tela: Collected Papers 1959, 2 , $162-76$. 
41. Chenhui, Y.; Yi, T.; Yapeng, T.; Yangyang, L.; Yucheng, H.; Xingtian, Y.; Wenxiu, Q., Achieving of Flexible, Free-Standing, Ultracompact Delaminated Titanium Carbide Films for High Volumetric Performance and Heat-Resistant Symmetric Supercapacitors. Adv. Funct. Mater. 2018, 28 (15), 1705487.

42. Lukatskaya, M. R.; Kota, S.; Lin, Z.; Zhao, M.-Q.; Shpigel, N.; Levi, M. D.; Halim, J.; Taberna, P.-L.; Barsoum, M. W.; Simon, P.; Gogotsi, Y., Ultra-high-rate pseudocapacitive energy storage in two-dimensional transition metal carbides. Nature Energy 2017, 2, 17105.

43. Khalil, A.; Liu, Q.; He, Q.; Xiang, T.; Liu, D.; Wang, C.; Fang, Q.; Song, L., Metallic 1T$\mathrm{WS}_{2}$ nanoribbons as highly conductive electrodes for supercapacitors. RSC Advances 2016, 6 (54), 48788-48791.

44. Yoon, S.; Kang, E.; Kim, J. K.; Lee, C. W.; Lee, J., Development of high-performance supercapacitor electrodes using novel ordered mesoporous tungsten oxide materials with high electrical conductivity. Chem. Comm. 2011, 47 (3), 1021-1023.

45. Hu, Z.; Ji, Z.; Lim, W. W.; Mukherjee, B.; Zhou, C.; Tok, E. S.; Sow, C.-H., K-Enriched $\mathrm{WO}_{3}$ Nanobundles: High Electrical Conductivity and Photocurrent with Controlled Polarity. ACS Applied Materials \& Interfaces 2013, 5 (11), 4731-4738.

46. Julien, C.; Yebka, B.; Porte, C., Effects of the lithium intercalation on the optical band edge of $\mathrm{WS}_{2}$. Solid State Ionics 1998, 110 (1), 29-34.

47. Kresse, G.; Hafner, J., Ab initio molecular-dynamics simulation of the liquid-metalamorphous-semiconductor transition in germanium. Phys. Rev. B 1994, 49 (20), 14251.

48. Kresse, G.; Furthmüller, J., Efficient iterative schemes for ab initio total-energy calculations using a plane-wave basis set. Phys. Rev. B 1996, 54 (16), 11169-11186. 
49. Perdew, J. P.; Burke, K.; Ernzerhof, M., Generalized gradient approximation made simple. Phys. Rev. Lett. 1996, 77 (18), 3865-3868.

50. Hellman, O.; Abrikosov, I. A.; Simak, S. I., Lattice dynamics of anharmonic solids from first principles. Phys. Rev. B 2011, 84 (18), 180301.

51. Hellman, O.; Steneteg, P.; Abrikosov, I. A.; Simak, S. I., Temperature dependent effective potential method for accurate free energy calculations of solids. Phys. Rev. B 2013, 87 (10), 104111.

52. Baroni, S.; de Gironcoli, S.; Dal Corso, A.; Giannozzi, P., Phonons and related crystal properties from density-functional perturbation theory. Rev. Mod. Phys. 2001, 73 (2), 515-562.

53. Giannozzi, P.; Baroni, S.; Bonini, N.; Calandra, M.; Car, R.; Cavazzoni, C.; Ceresoli, D.; L. Chiarotti, G.; Cococcioni, M.; Dabo, I.; Corso, A. D.; Gironcoli, S. d.; Fabris, S.; Fratesi, G.; Gebauer, R.; Gerstmann, U.; Gougoussis, C.; Kokalj, A.; Lazzeri, M.; Martin-Samos, L.; Marzari, N.; Mauri, F.; Mazzarello, R.; Paolini, S.; Pasquarello, A.; Paulatto, L.; Sbraccia, C.; Scandolo, S.; Sclauzero, G.; P. Seitsonen, A.; Smogunov, A.; Umari, P.; M. Wentzcovitch, R., QUANTUM ESPRESSO: a modular and open-source software project for quantum simulations of materials. $J$. Phys. Cond. Matter 2009, 21 (39), 395502.

54. Moruzzi, V. L.; Janak, J. F.; Schwarz, K., Calculated thermal properties of metals. Phys. Rev. B 1988, 37 (2), 790-799.

55. Momma, K.; Izumi, F., VESTA 3 for three-dimensional visualization of crystal, volumetric and morphology data. J. Appl. Crystallogr. 2011, 44 (6), 1272-1276.

56. Ghidiu, M.; Halim, J.; Kota, S.; Bish, D.; Gogotsi, Y.; Barsoum, M. W., Ion-Exchange and Cation Solvation Reactions in $\mathrm{Ti}_{3} \mathrm{C}_{2}$ MXene. Chem. Mater. 2016, 28 (10), 3507-3514. 